\title{
Optimale Analgesie bei Nierensteinkolik
}

\author{
Bei der akuten Nierensteinkolik erweisen sich $75 \mathrm{mg}$ Diclofenac i.m. als analgetisch \\ effektiver als die intravenöse Gabe von 0,1 mg/kg Morphin oder $1 \mathrm{~g} / 100 \mathrm{ml}$ Paracetamol.
}

_ Die Schmerzen bei der akuten Nierensteinkolik gehören zu den schlimmsten, die ein Mensch erleben kann. In den westlichen Industrieländern stieg die Inzidenz in den letzten zehn Jahren um über $50 \%$. Wohl jeder praktizierende Arzt erlebt mehrfach im Jahr einen Patienten mit derartigen Beschwerden. Doch besteht keine Einigkeit über die optimale analgetische Therapie.

Im Verlauf eines Jahres wurden in der Nothilfe der Universitätsklinik von Doha 1.645 Patienten mit akuter Nierensteinkolik in drei Gruppen randomisiert. 547 Patienten erhielten $75 \mathrm{mg}$ Diclofenac i.m., 548 bekamen $1 \mathrm{~g} / 100 \mathrm{ml}$ Paracetamol i.v., und 549 wurde $0,1 \mathrm{mg} / \mathrm{kg}$ Mor- phin i.v. verabreicht. In einer Intentionto-treat-Analyse wurde ermittelt, ob sie nach 30 Minuten eine mindestens 50\%ige Verringerung des Schmerz-Scores erreichten.

Bei 1.316 Patienten wurden Konkremente im Ureter diagnostiziert. Der primäre Endpunkt wurde unter Diclofenac von $68 \%$, unter Paracetamol von $66 \%$ und unter Morphin von $61 \%$ der Teilnehmer erreicht. Im Vergleich zu Morphin war Diclofenac signifikant effektiver bei der Schmerzreduktion, während zwischen Morphin und Paracetamol kein signifikanter Unterschied bestand. Unerwünschte Arzneimittelwirkungen traten unter Morphin bei 19 Patienten
(3\%) auf, in den beiden anderen Gruppe dagegen nur bei jeweils sieben (1\%).

- Pathan SA et al. Delivering safe and effective analgesia for management of renal colic in the emergency department: a double-blind, multigroup, randomised trial. Lancet. 2016;387:1999-2007

\section{KOMMENTAR}

Wir nehmen es zur Kenntnis und wundern uns, dass es eine derart schlichte Studie zu einem Allerweltsthema in eine der bedeutendsten Fachzeitschriften geschafft hat.

Prof. Dr. med. H. S. FüeßI

Themenhinweis: In MMW 17/2016 werden wir uns im Schwerpunkt „Der urologische Notfall“ intensiv auch mit der Therapie der Nierensteinkolik befassen.

\section{Hinter dem Exanthem steckt ein brasilianisches Virus}

Ein 39-jähriger Mann suchte wegen einer fiebrigen Erkrankung mit Kopf-, Schluck- und Muskelschmerzen, einer Konjunktivitis und einem Ausschlag im Gesicht eine Nothilfe auf. Begleit-

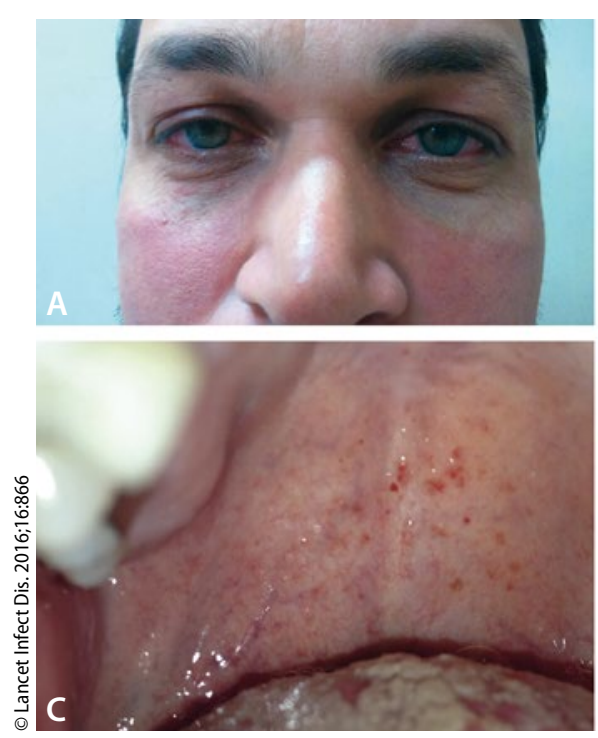

A: Exanthem im Gesicht, konjunktivale Injektion. B: Exanthem am Abdomen. C: Petechiale Blutungen am harten Gaumen. D: Druckdolenter Lymphknoten hinter dem Ohr.

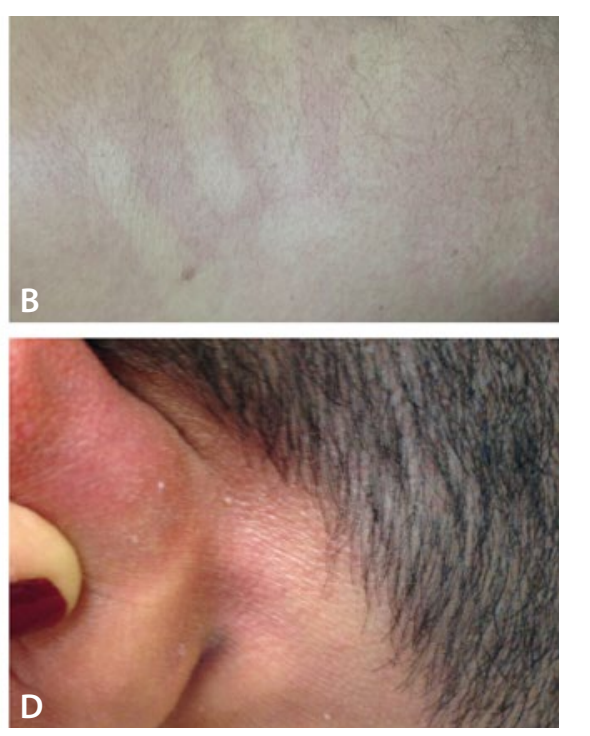

erkrankungen waren nicht bekannt. Bei der Untersuchung zeigten sich ein schmetterlingsförmiges Exanthem im Gesicht und eine konjunktivale Injektion (Abb. A) sowie ein makulöses

Exanthem im Bereich von Brust und Abdomen (Abb. B). Im Bereich des harten Gaumens fanden sich eine Rötung und petechiale Blutungen (Abb. C). Hinter dem linken Ohr tastete man einen druckdolenten, verschieblichen und weichen Lymphknoten von etwa $15 \mathrm{~mm}$ Durchmesser (Abb. D). Darüber hinaus fielen multiple kleinere, submandibuläre und zervikale Lymphknoten beidseits auf. Im Routinelabor bestanden keine Auffälligkeiten, im Urinstatus eine leichte Hämaturie.

Der Patient lebte in einer deprivierten Region von Rio de Janeiro. Serologische Untersuchungen auf Dengue, Zytomegalie, Toxoplasmose, EBV, Lues und HIV waren sämtlich negativ. Auch eine PCR für Dengue und Chikungunya ergab keinen pathologischen Befund. Erst die wegen der aktuellen Infektionswelle angelegte PCR von Zikavirus-RNA erbrachte ein positives Ergebnis. Die Behandlung war symptomatisch. 14 Tage nach der Erstvorstellung war der Patient vollständig beschwerdefrei.

Prof. Dr. med. H. S. FüeßI

- Brasil Petal. (patricia.brasil@ini.fiocruz.br).Exanthema associated with Zika virus infection. Lancet Infect Dis. 2016;16:866 